\title{
Commentaar bij HR 17 februari 2017, ECLI:NL:HR:2017:275 (X/Le Roux Fruit Exporters (Pty) Ltd) \\ Mr. T.M.C.Arons*
}

\begin{abstract}
De (hoofdelijke) aansprakelijkheid van de tweedegraadsbestuurder uit onrechtmatige daad jegens vennootschapscrediteuren van de kleindochter staat in deze bijdrage centraal. Meer in het bijzonder de vraag of de aansprakelijkheid ex artikel 2:11 BW van de tweedegraadsbestuurder een vorm van risicoaansprakelijkheid in het leven roept voor het gedrag van de medetweedegraadsbestuurder die een onrechtmatige daad pleegt jegens vennootschapscrediteuren van de kleindochter.
\end{abstract}

\section{Inleiding}

In deze zaak zet de Hoge Raad de reikwijdte van de doorbraakbepaling van artikel 2:11 van het Burgerlijk Wetboek (BW) uiteen. In hoogste instantie is nu bepaald dat ook bij aansprakelijkheid van een bestuurder-rechtspersoon op grond van artikel 6:162 $\mathrm{BW}$, de bestuurders van deze bestuurderrechtspersoon hoofdelijk aansprakelijk kunnen worden gesteld op grond van artikel 2:11 BW. De vraag die in deze bijdrage centraal staat, is hoe dit oordeel zich verhoudt tot de vereiste toerekenbaarheid in de zin van artikel 6:162 lid 1 en 3 BW. Is het gevolg van deze uitspraak dat bestuurders risicoaansprakelijk worden voor het handelen van hun medebestuurder(s)?

Het privaatrechtelijke uitgangspunt is dat een persoon slechts aansprakelijk is voor de schade die zijn onrechtmatig handelen tot gevolg heeft indien hem van die daad een verwijt kan worden gemaakt, of het een oorzaak betreft die krachtens de wet of de in het verkeer geldende opvattingen voor zijn rekening komt. ${ }^{1}$ Bij aansprakelijkheid van vennootschapsbestuurders voor hun handelen in de hoedanigheid van bestuurder jegens de vennootschap en derden ${ }^{2}$ wordt de toerekeningsmaatstaf

\footnotetext{
Mr. T.M.C. Arons is universitair docent financieel recht aan de Radboud Universiteit Nijmegen en senior jurist bij de Vereniging van Effectenbezitters te Den Haag.

1. Asser/Hartkamp \& Sieburgh 6-IV 2015/169.

2. Derden zijn in dit geval schuldeisers of aandeelhouders van de vennoot-
} schap. van artikel 6:162 lid 1 en 3 BW ingekleurd door het bekende ernstige-verwijtbaarheidscriterium. ${ }^{3}$

\section{Feiten}

Ik schets kort de achtergrond van deze zaak. De eiser in eerste aanleg is Le Roux Fruit Exporters (Pty) Ltd (hierna: Le Roux), handelaar in druiven. Le Roux verhandelt haar druiven via commissionairs. Le Roux' netto-opbrengst is de verkoopopbrengst minus douanekosten en de commissionairsvergoeding. In 2001 sluit Le Roux met Hyka BV (hierna: Hyka) een commissieovereenkomst. Enig bestuurder en 100\%-aandeelhouder van Hyka is Holding. Op haar beurt heeft Holding twee bestuurders, de natuurlijke personen broers A en B.

Hyka fraudeert door te hoge douanekosten en te lage verkoopopbrengsten in rekening te brengen ('commissiefraude'). Le Roux spreekt Hyka voor de geleden schade aan. In het zicht van faillissement van Hyka antedateert broer B een 'sale \& lease back'-overeenkomst tussen Hyka en Holding en onttrekt zodoende verhaalsvermogen aan Hyka ('vermogensonttrekking'). Hyka staakt haar onderneming; haar activiteiten worden voortgezet door de zustervennootschap Impala Fruit BV.

\subsection{Rechtbank}

Holding en broer A worden hoofdelijk veroordeeld tot schadevergoeding wegens de commissiefraude. Hen treft als feitelijk plegers een (persoonlijk) ernstig verwijt. ${ }^{4}$ Broer B wordt hiervoor niet veroordeeld. Wél wordt hij persoonlijk aansprakelijk gehouden voor de vermogensonttrekking door Holding, tenzij hij bewijst dat causaal verband tussen de vermogensonttrekking en Le Roux' schade ontbreekt.' Dit kan door aannemelijk te maken dat de boedel hoe dan ook onvoldoende baten

3. Van der Heijden \& Van der Grinten/Dortmond, Handboek voor de naamloze en de besloten vennootschap, Deventer: Kluwer 2013, nr. 240; Asser/Maeijer, Van Solinge \& Nieuwe Weme 2-II* 2009/469.

4. De commissiefraude van Holding en broer A heeft ook te gelden als gedraging van Hyka. In deze zin is Hyka ook een feitelijk pleger. Zie Asser/Maeijer \& Kroeze 2-I* 2015/85.

5. Rb. Arnhem 14 december 2011, ECLI:NL:RBARN:2011:BV0508. 


\section{Maandblad}

Ondernemingsrecht

zou hebben gehad om Le Roux' vorderingen te voldoen. Kortom, Holding is aansprakelijk op grond van de tweede pijler van Ontvanger/Roelofsen, ${ }^{6}$ dat wil zeggen het toerekenbaar bewerkstelligen of toelaten dat de vennootschap haar contractuele of wettelijke verplichtingen niet nakomt, met het voor de bestuurder voorzienbare gevolg dat een ander daar schade door zal lijden. ${ }^{7}$ Door de vermogensonttrekking kan Hyka niet aan haar contractuele verplichtingen voldoen. Volgens de rechtbank is broer B hiervoor persoonlijk aansprakelijk door toepassing van artikel 2:11 BW.

\subsection{Hof}

Het Gerechtshof Arnhem-Leeuwarden bekrachtigt het vonnis en overweegt ten aanzien van artikel 2:11 BW als volgt:

'In zodanig geval ligt het voor de hand om te oordelen dat voor aansprakelijkheid van de tweedegraadsbestuurder nog steeds moet worden geëist dat hem persoonlijk een voldoende ernstig verwijt kan worden gemaakt. Zouden [broer B] en [broer A] namelijk eerstegraads bestuurders van Hyka zijn geweest, dan zou voor aansprakelijkheid van [appellant] op grond van artikel 6:162 BW ook zijn vereist dat hem persoonlijk een voldoende ernstig verwijt kan worden gemaakt. Van de antimisbruikbepaling van artikel 2:11 BW kan niet de bedoeling zijn dat álle tweedegraads bestuurders zonder meer aansprakelijk zijn op de enkele grond dat één van hun collega bestuurders persoonlijk een voldoende ernstig verwijt kan worden gemaakt.'

\subsection{Hoge Raad}

Le Roux stelt tegen deze rechtsoverweging incidenteel cassatieberoep in. De Hoge Raad casseert. De op grond van artikel 6:162 BW vastgestelde aansprakelijkheid van bestuurderrechtspersoon Holding jegens de crediteur van Hyka, Le Roux, brengt op grond van artikel 2:11 BW hoofdelijke aansprakelijkheid van alle bestuurders van Holding met zich, tenzij ieder van hen voor zich stelt en zo nodig kan bewijzen dat hem geen persoonlijk ernstig verwijt treft. ${ }^{9}$ Broer B is dus in beginsel ook aansprakelijk voor de commissiefraude, tenzij hij zijn eventuele disculpatiegrond aannemelijk weet te maken.

6. HR 8 december 2006, ECLI:NL:HR:2006:AZ0758, Ondernemingsrecht 2007/36 m.nt. J.B. Wezeman (Ontvanger/Roelofsen).

7. De eerste pijler van Ontvanger/Roelofsen betreft de befaamde Beklameldoctrine: het door de bestuurder aangaan van verplichtingen namens de vennootschap in de wetenschap dat niet kan worden nagekomen en evenmin verhaal wordt geboden. Zie HR 6 oktober 1989, ECLI:NL:HR: 1989:AB9521, NJ 1990/286 m.nt. J.M.M. Maeijer (Beklamel).

8. Hof Arnhem-Leeuwarden 15 oktober 2013, ECLI:NL:GHARL: 2013:7697, JOR 2014/3 m.nt. S.M. Bartman \& X.D. van Leeuwen, JIN 2014/8 m.nt. J. van der Kraan, r.o. 4.3 .

9. HR 17 februari 2017, ECLI:NL:HR:2017:275, JOR 2017/121 m.nt. A.F.J.A. Leijten, Ondernemingsrecht 2017/79 m.nt. M. Mussche \& Y. Borrius, AAe20170523 m.nt. S.M. Bartman \& C.E.J.M. Hanegraaf, JIN 2017/51, r.o. 3.4.4.

\section{Commentaar}

\subsection{Stelplicht en bewijslastverdeling}

Het hof en de Hoge Raad volgen de meerderheidsopinie dat de doorbraakbepaling van artikel 2:11 BW in alle gevallen van wettelijke aansprakelijkheid van een bestuurder-rechtspersoon van toepassing is. ${ }^{10}$ Anders dan het hof eerder oordeelde, ${ }^{11}$ betekent dit volgens de Hoge Raad dat voor vestiging van de aansprakelijkheid van een bestuurder van een rechtspersoonbestuurder niet de aanvullende eis geldt dat de schuldeiser stelt, en zo nodig bewijst, dat ook die bestuurder persoonlijk een ernstig verwijt kan worden gemaakt. ${ }^{12}$ In essentie heeft dit een verschuiving van de stelplicht en bewijslast tot gevolg. In het normaaltype artikel 6:162-vordering moet de eiser immers stellen en zo nodig bewijzen dat aan alle elementen (onrechtmatige handeling, schade, causaal verband en toerekenbaarheid) is voldaan. Bij een artikel 6:162-vordering jegens de bestuurder van de bestuurder-rechtspersoon op grond van artikel 2:11 BW is het aan de gedaagde bestuurder om te stellen en zo nodig te bewijzen dat hem in de gegeven omstandigheden geen persoonlijk ernstig verwijt treft. De aansprakelijkheid van de bestuurders is een hoofdelijke. Individuele disculpatie is mogelijk, maar de stelplicht en bewijslast rusten bij ieder van de bestuurders.

In het vennootschapsrecht brengt de collectieve verantwoordelijkheid voor het bestuur een aansprakelijkheid van alle bestuurders ten opzichte van de vennootschap met zich. De individuele bestuurder kan zich disculperen door te stellen en zo nodig te bewijzen dat hem geen persoonlijk ernstig verwijt treft. In essentie gaat het hier dan ook niet om hoofdelijke aansprakelijkheid als bestuurder voor gedragingen van medebestuurders, maar om aansprakelijkheid voor eigen handelen en nalaten. Bij bestuurdersaansprakelijkheid geldt vanwege de collectieve verantwoordelijkheid wel een omkering van stelplicht en bewijslast. Als de aangesproken bestuurder erin slaagt zijn disculpatie aannemelijk te maken is hij niet aansprakelijk.

\subsection{Risicoaansprakelijkheid voor gedrag medebestuurder?}

Risicoaansprakelijkheid betreft alle vormen van aansprakelijkheid voor eigen gedragingen, voor andermans gedragingen of voor zaken waarbij geen sprake is van toerekening op basis van schuld. ${ }^{13}$ De vraag is of artikel 2:11 BW kennelijk moet worden opgevat als een wetsbepaling die voor een bestuurder van

10. Ik volsta met een verwijzing naar de belangrijkste handboeken: Asser/ Maeijer \& Kroeze 2-I* 2015/213; Asser/Maeijer, Van Solinge \& Nieuwe Weme 2-II* 2009/476; Slagter/Assink, Compendium ondernemingsrecht. Deel 1, Deventer: Kluwer 2013, par. 15.

11. Kritisch ten aanzien van die overweging (4.3) van het hof: P.D. Olden \& J.H.L. Beckers, Kroniek bestuurdersaansprakelijkheid 2013, in: M. Holtzer e.a. (red.), Geschriften vanwege de Vereniging Corporate Litigation 2013-2014 (Serie vanwege het Van der Heijden Instituut, deel 121), Deventer: Kluwer 2014, par. 8.1.2.

12. HR 17 februari 2017, ECLI:NL:HR:2017:275 (X/Le Roux Fruit Exporters (Pty) Ltd), r.o. 3.4.3.

13. Asser/Hartkamp \& Sieburgh 6-IV 2015/24. 
een bestuurder-rechtspersoon een risicoaansprakelijkheid jegens derden (schuldeisers en aandeelhouders van de vennootschap) voor gedragingen van zijn medebestuurder met zich brengt. Ik denk het niet. Er is in ieder geval geen sprake van een dergelijke risicoaansprakelijkheid voor een bestuurder van een rechtspersoon die niet op zijn beurt bestuurder van een andere rechtspersoon is. Deze bestuurder is niet aansprakelijk jegens derden voor het handelen van zijn medebestuurder. Immers, zijn aansprakelijkheid moet worden gestoeld op een hem persoonlijk te maken ernstig verwijt.

De Hoge Raad wijdt in dit arrest geen overwegingen aan de verhouding tot het toerekenbaarheidsvereiste van artikel 6:162 lid 3 BW. Dit is jammer, want dit betreft een centraal element in elke aansprakelijkheidsvordering tot schadevergoeding. Voor de vestiging van aansprakelijkheid van een rechtssubject voor de schade die zijn onrechtmatige daad heeft veroorzaakt, moet zijn daad aan hem kunnen worden toegerekend. ${ }^{14}$ Naast de aansprakelijkheid voor eigen handelen schrijft de wet ook voor dat bepaalde handelingen van een ander voor rekening en risico komen van degene die in een bijzondere verhouding tot deze ander staat (ouder-kind, ${ }^{15}$ werkgever-werknemer, ${ }^{16}$ opdrachtgever-opdrachtnemer ${ }^{17}$ en vertegenwoordigde-vertegenwoordiger ${ }^{18}$ ).

\subsection{Groepsaansprakelijkheid}

Een ander voorbeeld van toerekening van de daad van een ander is de groepsaansprakelijkheid ex artikel 6:166 BW. De rechtvaardiging voor deze toerekening is het vrijwillig genomen individuele besluit tot groepsdeelname. ${ }^{19}$ De onrechtmatige gedraging gepleegd door een van de tot een groep behorende personen brengt aansprakelijkheid van alle groepsleden met zich indien de onrechtmatigheid is gelegen in de kansaanvaarding van het aldus toebrengen van voorzienbare schade. Deze kans op schadetoebrenging had de groepsleden behoren te weerhouden van hun gedragingen in groepsverband. Schending van een wettelijke plicht door een van de groepsleden brengt dus geen groepsaansprakelijkheid mee. ${ }^{20}$ Voor aansprakelijkheid van het groepslid is ook nog vereist dat zijn deelneming aan de gedragingen in groepsverband hem als een onrechtmatige daad kunnen worden toegerekend. ${ }^{21}$ Het groepslid kan zich niet disculperen door te stellen dat hij niet de eigenlijke schadeveroorzakende daad verrichtte. Het betreft daadwerkelijk hoofdelijke aansprakelijkheid als groepslid voor gedragingen van een ander. Uiteraard kan een aangesprokene wel stellen en zo nodig bewijzen dat hij geen groepslid was.

14. Asser/Hartkamp \& Sieburgh 6-IV 2015/98.

15. Art. 6:169 BW.

16. Art. $6: 170 \mathrm{BW}$.

17. Art. 6:171 BW.

18. Art. 6:172 BW.

19. Zie ook N. Peters \& M. Goorts, Artikel 6:166 BW: onbekend maakt onbemind?, AV\&S 2012/21.

20. Asser/Hartkamp \& Sieburgh 6-IV* 2011/128.

21. Asser/Hartkamp \& Sieburgh 6-IV* 2011/127.
Sporadisch worden bestuurders van vennootschappen en vennootschappen die in groepsverband frauduleus handelen ten opzichte van een derde op grond van artikel 6:166 BW hoofdelijk aansprakelijk gehouden. ${ }^{22}$ Overigens verdient hierbij opmerking dat niet licht voldaan wordt aan de bewijslast dat sprake is van het plegen van een onrechtmatige gedraging jegens een derde door aandeelhouders respectievelijk bestuurders van een vennootschap in groepsverband met deze vennootschap. ${ }^{23}$ De bestuurder van een vennootschap en een derde die als groep frauduleus handelen ten opzichte van deze vennootschap zijn eveneens op grond van artikel 6:166 BW hoofdelijk aansprakelijk voor de schade die de vennootschap lijdt. $^{24}$

\section{Concluderende opmerkingen}

Terug naar de onderhavige casus. Is er bij bestuurdersaansprakelijkheid ex artikel 2:11 BW nu sprake van een risicoaansprakelijkheid voor daden van medebestuurders? Het verweten handelen waarvoor Le Roux hoofdelijke veroordeling van broer B wenst, is de commissiefraude. Deze commissiefraude is een onrechtmatige daad van Holding, omdat zij daarmee bewerkstelligde dat Hyka haar contractuele verplichting jegens Le Roux niet na kon komen. Broer A heeft, ongeacht of de vordering rechtstreeks wordt gebaseerd op artikel 6:162 BW of via artikel 2:11 BW, dezelfde onrechtmatige daad gepleegd. $\mathrm{Hij}$ is immers de feitelijk pleger; zijn (feitelijk) handelen wordt aan Holding toegerekend. Broer B wordt als bestuurder van Holding hoofdelijk aansprakelijk gehouden - tenzij hij individuele disculpatieomstandigheden stelt en zo nodig bewijst voor het feitelijk handelen van broer $\mathrm{A}$ in de hoedanigheid van bestuurder. Kortom, er is geen sprake van risicoaansprakelijkheid ex artikel 2:11 BW voor het handelen van een medebestuurder. De bestuurder is alleen aansprakelijk als hem een verwijt te maken valt, bijvoorbeeld omdat hij wist van de fraude en naliet maatregelen te treffen.

De vraag is of het door de Hoge Raad in de Spaanse Villa- en Breeweg/Wijnkamp-arresten ${ }^{25,26}$ gemaakte onderscheid tus-

22. Zie Peters \& Goorts 2012, par. 7, verwijzend naar Rb. Rotterdam 30 juni 2010, ECLI:NL:RBROT:2010:BN4213 (KvK/Kantoor voor Klanten I) en Rb. Rotterdam 10 augustus 2011, ECLI:NL:RBROT:2011:BR6484 (KvK/Kantoor voor Klanten II). Zie recent Rb. Den Haag 24 juni 2015, ECLI:NL:RBDHA:2015:8773 (Stichting Cultureel Beheer Paleisstraat 8, Doopsgezinde Gemeente Den Haag en Stichting Steunfonds Oldeslo/ $\mathrm{X} \& \mathrm{Y})$. Voor een goed overzicht, zie A.W. van der Veen, De groepsaansprakelijkheid ex artikel 6:166 BW in corporate litigation, in: M. Holtzer e.a. (red.), Geschriften vanwege de Vereniging Corporate Litigation 2015-2016 (Serie vanwege het Van der Heijden Instituut, deel 134), Deventer: Kluwer 2016.

23. Zie voor een recent voorbeeld waarin de rechter oordeelde dat er geen sprake was van een groep: Hof 's-Hertogenbosch 4 oktober 2016, ECLI:NL:GHSHE:2016:4406.

24. Rb. Amsterdam 24 april 2013, ECLI:NL:RBAMS:2013:4756.

25. HR 23 november 2012, ECLI:NL:HR:2012:BX5881, JOR 2013/40 m.nt. W.J.M. van Andel en K. Rutten, JA 2013/59 m.nt. F. Leopold en R. van Vlooten, Ondernemingsrecht 2013/47 m.nt. M.J. Kroeze, NJ 2013/302 m.nt. P. van Schilfgaarde, AA20130125 m.nt. M.J.G.C. Raaijmakers (Spaanse Villa).

26. HR 18 september 2015, ECLI:HR:2015:2745, JOR 2015/289 m.nt. S.C.J.J. Kortmann (Breeweg/Wijnkamp c.s.). 


\section{Maandblad}

sen het handelen in de hoedanigheid van bestuurder en het handelen buiten de bestuursfunctie om nog gevolgen heeft voor de aansprakelijkheid van medebestuurders. Dit lijkt mij van wel. Een bestuurder is uiteraard niet ansprakelijk (ook niet via art. 2:11 BW) als de onrechtmatige daad van zijn medebestuurder is gelegen in een handelen dat niet in de hoedanigheid van bestuurder is geschied. Het betreft dan niet een handeling namens of voor de vennootschap. Bestuurders zijn dan ook niet aansprakelijk voor beroepsfouten die zijn gemaakt door een medebestuurder in de uitvoering van een overeenkomst die de vennootschap heeft gesloten met een client. $^{27}$

Kortom, de bestuursfunctie betekent niet een zodanige verhouding tot medebestuurders dat de wet daaraan een risicoaansprakelijkheid verbindt. Het arrest van de Hoge Raad van 17 februari 2017 over de toepasbaarheid van de doorbraakbepaling (art. 2:11 BW) bij artikel 6:162-vorderingen heeft deze implicatie ook niet. De bestuurder is en blijft slechts aansprakelijk voor zijn eigen handelen en nalaten. Wel komt op hem in bepaalde door de wet aangewezen gevallen (zoals 'tussenplaatsing' van een bestuurder-rechtspersoon) een stelplicht en bewijslast te rusten dat hem geen persoonlijk ernstig verwijt treft voor het onrechtmatig handelen van een medebestuurder, indien hij door derden wordt aangesproken.

27. De reikwijdte van de leer Ontvanger/Roelofsen en de verhouding tot de arresten Spaanse Villa en Breeweg Wijnkamp zijn laatstelijk fraai uiteengezet in de conclusie van A-G Hartlief van 9 december 2016 in de zaak Attitude Group BV/Multi Business Solutions Holding BV, ECLI:NL:PHR:2016:1264, ovw. 4.13-4.21. 